\title{
Tenant Mix Variety in Regional Shopping Centres: Some UK Empirical Analyses
}

\author{
Tony Shun-Te Yuo*\#, Neil Crosby*, Colin Lizieri* and Philip McCann** \\ *Department of Real Estate \& Planning \\ $* *$ Department of Economics \\ The University of Reading Business School \\ Whiteknights, Reading RG6 6AW $\underline{\text { UK }}$ \\ \#Corresponding Authors: c.m.lizieri@rdg.ac.uk tonyyuo@yahoo.com
}

Key words: retail agglomeration, inter-store externalities, core-periphery model, shopping centre image

\section{Introduction}

The planned shopping centre or mall has become an important part of contemporary life style. It has been changing patterns of shopping as well as social and recreational activities since its first appearance in 1920s in the US: now malls are found almost everywhere in the world (Brown, 1992; Urban Land Institute, 1999). One of the major reasons for this creation was to engineer a better shopping environment and, thus, gain better operational performance. In this created shopping environment, negative agglomeration effects can be more easily eliminated or keep under proper control, further reinforcing favourable interactions among tenants. Consequently, agglomeration economies generated from the clustering of tenants are one of the most significant benefits to be pursued by retail managers.

This cluster of tenants is referred to as the "tenant mix" by the shopping centre industry. It has been a long-term concern for shopping centre managers/operators and researchers in this area ${ }^{1}$ because of its significance in establishing the shopping centre's image and enhancing the synergies within the shopping centre. However, no satisfactory suggestions have been made for the best strategy for tenant mix; owners merely followed some rules of thumb or their own experience (Anikeeff, 1996; Brown, 1991; Greenspan, 1987). Nevertheless, we know, from agglomeration theory, that variety is an important factor in increasing productivity in the traded-good sector (Fujita, 1989; Fujita and Thisse, 2002). However, there is a still lack of operational principles to advise centre managers/operators how to perform this crucial element for creating a pleasant shopping environment.

\footnotetext{
${ }^{1}$ See, for example, Abratt et al., 1985; Anikeef, 1996; Brown, 1992; Downie et al., 2002; Gerbich, 1998; Greenspan, 1987; Kirkup \& Rafiq, 1994; Yuo et al., 2003.
} 
Consequently, this research attempts to reveal some information concerning beneficial patterns of tenant mix variety. A database is established for this purpose, covering the tenant lists of all regional shopping centres in the UK. A total of 148 shopping centres are included in the database for the year 2002. Three sets of tests of the beneficial patterns of tenant mix variety are conducted: first, given the proposition of the relationship between variety and performance (rent), five operational variety indices size of shopping centre, number of units, average unit size, number of retail/service categories and number of brands - will be examined through econometric methods; second, the impact of concentration or diversity in tenant mix patterns are tested using Herfindahl indices of retail/service categories and the number of brands within each shopping centre; third, the value of concentration on core categories and brands is tested by a factor analysis used to extract the exact core/periphery retail/service categories from the tenant lists of the 148 regional shopping centres. The paper focuses exclusively on tenant mix variables. Prior work examined rent formation in UK shopping centres in more detail (Yuo et al., 2003).

\section{Literature Review}

\section{2-1 Agglomeration economies and increasing returns}

Tenant mix variety is the combination of homogeneous and heterogeneous agglomeration that generates increasing returns from both scale and scope. Firms producing the same traded good can enjoy the advantages of agglomeration. "Firms producing the same traded good may find it profitable to agglomerate ...These agglomeration economies are often called (Marshallian) external economies because they are a consequence of an enlargement of the total activity level of the industry in the same city and hence are beyond the control of each individual firm" (Fujita, 1989, pp271-272). Firms with product heterogeneity also benefit from agglomeration. Fischer and Harrington (1996, p281) thus suggested "greater product heterogeneity increases consumer search, which raises the amount of shopping at a cluster." These agglomeration economies imply that the increasing returns to scale (or economies of scale) must be achieved by the firms in the cluster (McCann, 2001, p55). Return to scale is the relationship between input of resources and the outputs of the production function: increasing returns to scale implies that the outputs of the production function are greater than the scales of the inputs to the production system. 
In addition to economies of scale, the advantages of agglomeration also come from scope, “... a basic and intuitively appealing property of production: cost savings which result from the scope (rather than the scale) of the enterprise. There are economies of scope where it is less costly to combine two or more product lines in one firm than to produce them separately" (Panzar and Willig, 1981, p268). Mainly economies of scope are generated from the sharing of inputs and costs. Benefits come from the economies of sharing in the joint production of a multiple-product. For urban economies, these economies of scope save the costs of inputs or transportation at spatial agglomeration in combining multiple-products (Goldstein and Gronberg, 1984).

\section{2-2 Variety, productivity and the core-periphery relationship}

In urban economics, variety is one of the most significant reasons for forming a city; both central place theory and agglomeration economies theory tell us that variety always plays an important role as a favourable factor in industry and commercial agglomeration. Fujita (1989, p272) suggested that “...increasing returns to scale in the service industry and the desire of the traded-good industry to employ a variety of intermediate services may provide the basic forces of industrial agglomeration in a city; that is, the larger the variety of available intermediate services, the higher will be the productivity of the traded-good industry in a city." As a city needs variety, so does a shopping centre. The larger the shopping centre, the more variety it needs. The greater the variety it has, the higher the productivity it can achieve.

Consequently, clustering of retailers can generate variety and increase attraction. In retail location theory, Nelson (1958) first showed that the tendency of retail clustering is based on the theory of Cumulative Attraction and the Principle of Compatibility. In his research, the theory of cumulative attraction suggested “...a given number of stores dealing in the same merchandise will do more business if they are located adjacent or in proximity to each other than if they are widely scattered" (Nelson, 1958, p58). This is the major reason for retail agglomeration. This retail store spatial affinity was also observed by Getis and Getis (1976). In their research, they suggested that retail store spatial affinities are based on three location theories: the theory of land use and land value, central place theory, and the theory of tertiary activity. After examining retail stores in the CBDs of a sample of cities in the US, they confirmed that retail store spatial affinities do exist and matched them with the propositions of Central Place theory (Getis and Getis, 1976). 
Krugman (1991) also makes suggestions about the beneficial patterns for agglomeration behaviour. One of the most significant patterns is the core-periphery relationship. He suggested that the agglomeration of a country has an "industrial core”- "agriculture periphery” relationship, so as to gain scale economies while, at the same time, minimising transport costs. As the agricultural product is characterized both by constant returns to scale and by intensive use of immobile land, the manufactured product is characterized by increasing returns to scale and modest use of land: "because of economies of scale, production of each manufactured good will take place at only a limited number of sites” (Krugman, 1991, p485).

This core-periphery relationship in agglomeration can also explain retail agglomeration in a shopping centre. Instead of manufactures, the "core” of a regional shopping centre is the agglomeration of anchors, high comparison goods and services, and the popular/fashion retail categories. The periphery, on the other hand, is the retail/service providers in a supplementary role. Therefore, the retailers locating in the "peak pitch" of pedestrian flows are the "core" stores, whilst periphery stores are usually located in the surrounding locations. Later in our empirical study, this core-periphery relationship in UK regional shopping centres will be tested in order to find out the core categories in tenant mix variety. The existence of this relationship can help to explain the importance of the image and "theme" for a centre. Only the right pattern with correct core-periphery categories can establish the right centre image for its theme.

\section{2-3 Tenant mix variety}

The shopping centre is an agglomeration of various retailers and commercial service providers within a well planed, designed and managed building or a group of buildings as a unit (ICSC, 2002; Urban Land Institution, 1999). This definition suggests the agglomeration of retail/service activities in a shopping centre is well planned and highly controlled by the centre manager/operator. Therefore, the interactive forces among tenants, that is the inter-store externalities, can be internalised/managed to maximise profits for the whole shopping centre (Yuo et al., 2003). This cluster of retail and service providers in shopping centres is termed the “tenant mix" (Bruwer, 1997; Downie et al., 2002; Kirkup and Rafiq, 1994). The variety of retail/service categories and brands is the result of this mixture of various tenants. 
Previous research suggested that tenant mix is one of the most crucial factors in the success of a shopping centre (Abratt et al., 1985; Anikeeff, 1996). It is certainly one of the most crucial elements in establishing the image of a shopping centre. However, some managers and researchers still treat tenant mix as a "puzzle" in shopping centre management (Bruwer, 1997; Greenspan, 1987). The reason is because tenant mix seems to be an art, performed by the centre management team. A regional shopping centre $^{2}$ usually contains more than 100 retail units: thus the possible tenant mix arrangements of retail/service categories and brands are almost infinite. Since each possible mixture of tenants makes a distinctive contribution to the image of the shopping centre, how is it possible for us to identify an "ideal" or "balanced" tenant mix for a certain shopping centre? Moreover, tenant mix is not a static condition: the market changes over time, as do the customer preferences and fashion trends. Therefore, even the "ideal" condition achieved in one season or period might not be suitable for the next one. Besides, the retail industry is almost a perfectly competitive market: thus, the actions of competitors always dramatically influences marketing strategies. Consequently, centre managers/operators have to adjust their tenant mix constantly to keep up with the market trends. Under these circumstances, it is not surprising to find that an ideal tenant mix can be a puzzle for centre managers/operators.

A good tenant mix includes a variety of compatible (or complementary) retail/service providers, and an efficient space allocation (both size and number) and proper tenant placement that encourages the interchange of customers and retail activities. In a wider perspective, it should also include sufficient public facilities and services, both in terms of the quality and quantity demanded. The essentials that enhance the quality of the centre's shopping environment, to satisfy shoppers' needs, such as goods and services, convenience, excitement, and amenities, are all part of the elements of an ideal tenant mix.

\footnotetext{
${ }^{2}$ Here, we define a regional shopping centre as a shopping centre with over 300,000 sq ft (28,000 sq m) gross leasable area.
} 


\section{Hypotheses, data and models}

\section{3-1 Propositions and Hypotheses}

Despite of the instability and volatility of tenant mix noted in the previous section, there are some principles and patterns that increase agglomeration economies from retail clustering. From the above review of agglomeration and retail literatures, three propositions about the beneficial patterns of retail/service categories can be extracted for further empirical examination.

Proposition 1: the higher the variety in categories and brands the higher the rent First of all, the positive relationship between variety and productivity suggest that the higher the diversity in product variety, the higher the operational performance. This product variety may come from two aspects of tenant mix, the different retail/service categories and the brands within each of these categories.

\section{Proposition 2: concentration in category but diversity in brands}

The second proposition in this research is the concentration and diversity relationship. Although variety means diversity in retail/service categories and brands, there still should be a pattern in the distribution of these categories and brands. Since tenant mix plays a crucial part in establishing the image of the shopping centre, themes and attractions of image to be focused. Therefore, each shopping centre should concentrate on certain retail/service categories, focusing on its target market segmentation. This is, in effect, the core-periphery relationship proposition.

Proposition 3: concentration in core categories increases the rent.

Thirdly, from the full tenant lists of UK regional shopping centre, we should be able to extract the exact core and periphery retail/service categories. This will provide us with information as to which retail/service categories should be focused upon in a regional shopping centre. Since the regional shopping centre is near the top of the retail hierarchy, these "core categories” should be consistent with central place theory, and include categories such as comparative, luxury and durable goods.

There are a number of indices which could be used to reveal information on tenant mix variety in a shopping centre, such as the size of the centre, the number of units, the average size of units, the number of retail/service categories and the number of brands. Each of these five indices provides us some information on different aspects of tenant mix variety. 
Three of these: the size of centre, the number of units and the average unit size; are size-oriented variables that can indirectly provide variety information linked to space capacity. The number of retail/service categories and the number of brands within the shopping centre, on the other hand, provide us with direct information on the variety of goods and services. Since variety is expected to be a positive factor with shopping centre rent, all these five variables representing these indices should be positively related to rent /sq ft. Therefore, the first hypothesis is:

$\mathbf{H}_{\mathbf{a}}$ : All of the five variables, namely the size of the centre, the number of units, the average size of units, the number of retail/service categories and the number of brands, are positively related to rents

In order to test the meaning of these concentration-variety/diversity arguments in the shopping centre, we established our hypothesis for testing tenant mix variety:

$\mathbf{H}_{\mathbf{b}}$ : The more concentrated the retail categories, the higher the rent.

It is necessary to establish the "core" of the agglomeration, namely the image or the theme of a shopping centre.

$\mathbf{H}_{\mathbf{c}}$ : The more the diversity of brands, the higher the rent.

The customers thus have a deeper selection of similar goods to fulfil their need to compare prices and quality.

Regional shopping centres are ranked highest in retail centre hierarchies: both Christaller and Lösch showed in Central Place theory that all kinds of goods and services and other economic activities are available in the highest rank of city (or here the retail centre). Therefore, we suggest that a regional shopping centre should have all kinds of retail/service tenants. Nevertheless, these two further hypotheses propose that the agglomeration of these tenants should have a tendency for concentration in particular retail categories to establish their image and themes (the core). At the same time, the brands within each retail category should be as diverse as possible to provide a wide selection and allow for comparison of prices by customers ${ }^{3}$.

\footnotetext{
${ }^{3}$ The selection and comparison provide by regional shopping centres should include all the retail goods: comparison goods, convenience goods, impulsive goods and other leisure, entertainment and commercial services. The definitions of these different retail goods see Northern (1984) and ULI (1999).
} 
The last test of retail/service categories is to identify the "core" retail/service categories from the UK regional shopping centre database. A full tenant list of all the UK regional shopping centres formed the basis for extraction of representative factors by multivariate data analysis. These extracted factors, which contain the higher loadings on the core retail/service categories, also need to be tested in regression models to show their relationship with rent. These factors with high loadings of core retail/service categories should have a positive significant relationship with rent/ sq ft. Thus the hypothesis is suggested as:

$\mathbf{H}_{\mathbf{d}}$ : The higher the "core" factor scores the higher the rent.

\section{3-2 Data}

The data collection exercise targeted all the regional shopping centres in the UK for both performance and characteristics information. In the final database, a total of $148^{4}$ regional shopping centres meeting the definition of above 300,000 square foot were included. The database was collated from multiple sources, including Freeman's Guide (Baum, 2001), Shopping Centre and Retail Directory (William Reed Directories, 2001), and EGI's Shopping Centre Research and Market Place databases. From these sources, two linked datasets were created. The first contains detailed characteristic information for these 148 shopping centres, including the tenant lists of all the shopping centres with 11,918 detailed records of individual tenants with name, and retail category, as well as country of origin. However, the availability of individual information in terms of size of units, rental levels, and service charges is limited. The second dataset provides information on unit size and rental levels for individual units within the 148 shopping centres from different sources. In the second dataset, some 1,930 records with detailed occupier information were collected including name of occupier, rental level (total rent per annum or rent per square foot/metre), retail activities, size of tenants (measured in square foot).

All the shopping centre detailed information was collected in 2002. The tenant lists of shopping centres are dated for the period January 2002 to March 2002. Since tenant composition will change over time, setting a specific date for data collection is crucial in maintaining data quality for later analysis. However, as discussed further below, the dates of rent level data varied considerably.

\footnotetext{
${ }^{4}$ These 148 shopping centres are narrowed down from a total of 214 shopping centres drawn from different sources of data, by eliminating the centres that are under construction, not located in mainland Britain, or categorized as shopping/retail parks.
} 


\section{3-3 Models: regression models and factor analysis}

\section{3-3-1 Data adjustment and definitions}

Several adjustments are needed prior to analysis. The most important adjustment is to the dependent variable, the rent variable. The rental data available was mostly recent but included earlier dates with a very small number (around 2.5\%) being pre-1990. We use the following formula to adjust rents to a common 2002 date:

$$
\bar{y}_{i}=\frac{Y i t}{S i} \prod_{t_{n}}\left(1+r_{j t_{n}}\right)
$$

$\bar{y}_{i}$ : adjusted retail rent per sq $\mathrm{ft}$ of retail $i$

$Y_{i t}$ : total rent per annum of retailer $i$ at year $\mathrm{t}$.

$$
S_{i} \text { : unit size of retailer } i \text { (sq ft) }
$$

$r_{j t_{n}}$ : retail rental growth rate in region $\mathrm{j}$ at year $t_{n}$

$t_{n}$ : years from the time of occupation to year 2002

The variables used in later models are defined as Table 1:

\begin{tabular}{|l|l|l|}
\hline \multicolumn{3}{|c|}{ Table1: Definitions of variables } \\
\hline \multicolumn{1}{|c|}{ Variables } & \multicolumn{1}{|c|}{ Description } & Data Type \\
\hline Lnrentsqft & Logarithm of rent per square foot of the occupier retailer i. & Numerical \\
\hline RRRL & The appropriate regional retail rental level in April 2002 & Numerical \\
\hline STenant & $\begin{array}{l}\text { Strong tenants, from Freeman's Guide 2002, all top retailer/service } \\
\text { providers in each retail categories, 1(top retailer), 0(non-top retailer) }\end{array}$ & Dummy \\
\hline SCage & Shopping centre age from original opening date & Numerical \\
\hline Sgrouping & $\begin{array}{l}\text { Size grouping of tenants (classified as anchor, major space user, } \\
\text { standard large, standard small, and small tenants) }\end{array}$ & Categorical \\
\hline Ngrouping & $\begin{array}{l}\text { Number of outlets grouping (classified as strong, medium, weak chain, } \\
\text { and independent retailer) }\end{array}$ & Categorical \\
\hline Footfalls & The average weekly footfall of the shopping centre & Numerical \\
\hline SCsize & Shopping centre size in sq ft & Numerical \\
\hline SCunit & Number of units in the shopping centre & Numerical \\
\hline Ausize & Average unit size of each shopping centre & Numerical \\
\hline NOFCATE & Number of categories in each shopping centre & Numerical \\
\hline NOFBRANDS & Number of brands in each shopping centre & \\
\hline C & Constant & \\
\hline
\end{tabular}




\section{3-3-2 Testing the variety indices}

Five variables related to tenant mix variety are examined individually: a) size of shopping centre; b) number of units within a shopping centre; c) average unit size in a shopping centre; d) number of retail/service categories within a shopping centre; and e) number of brands within a shopping centre. The related models used here are presented as Model 1 to Model 5:

Model 1: $\quad$ Lnrentsqft $=f($ Sgrouping, SCsize $)$

Model 2: $\quad$ Lnrentsqft $=f($ Sgrouping, SCunits)

Model 3: $\quad$ Lnrentsqft $=f($ Sgrouping, Ausize $)$

Model 4: $\quad$ Lnrentsqft $=f($ Sgrouping, NOFCATE $)$

Model 5: $\quad$ Lnrentsqft $=f($ Sgrouping, $\quad$ NOFBRANDS $)$

The major purpose for these five models is to test hypothesis $H_{a}$, showing the direction of coefficient and significance between these five variables and rent/sq ft. To focus on the tenant mix variables, the models are kept as parsimonious as possible. This is because preliminary tests show high multicollinearity problems: hence the nned to test separately. Moreover, from preliminary tests and prior work (Yuo et al. 2003), the size of unit for each tenant appears to be the most significant variable related to rent; therefore it is used as an adjusting variable to improve the degree of explanation in the models.

\section{3-3-3 Testing the concentration/diversity of retail categories and brands}

To test concentration/diversity issues, we established Herfindahl indeces of each shopping centre. A Herfindahl index is a measure of the concentration of the production in an industry and is calculated as the sum of the squares of market share for each firm. The major benefit of the Herfindahl index in relation to such measures as the concentration ratio is that it gives more weight to larger firms (retail categories) (AmosWeb, 2003; Wikipedia, 2003). 
The Herfindahl index for retail categories is defined as:

$$
G_{c i}=\sum_{c r=1}^{n}\left(\frac{E_{c r}}{E_{i s}}\right)^{2}
$$

Here

$G_{c i}$ : The Herfindahl index for retail categories of the shopping centre $i$.

$E_{i s}$ : The total unit number in shopping centre $i$.

$E_{c r} \quad$ : The total unit number in retail category r.

$\mathrm{n}$ : total number of retail categories in the shopping centre industry

The definition of the Herfindahl index for retail/service brand names is similar; the only difference is in substituting the retail categories for retail brands.

$$
G_{B i}=\sum_{B K=1}^{m}\left(\frac{E_{B K}}{E_{i s}}\right)^{2}
$$

Here

$G_{B i}$ : The Herfindahl index for retail brands of shopping centre $i$.

$E_{i s}$ : The total unit number in shopping centre $i$.

$E_{B K}$ : The total unit number in retail brands $\mathrm{k}$.

$\mathrm{m}$ : total number of brands in shopping centre industry

In Model 6 and Model 7, our objective is to test the two Herfindahl indices, thus these two models are as follows:

Model 6:

$$
\text { Lnrentsqft }_{i}=f\left(R R R L, \text { STenant, Sgrouping, SCage, Ngrouping, Footfalls, } G_{C i}\right)
$$

Model 7:

Lnrentsaft $_{i}=f\left(R R R L\right.$, STenant, Sgrouping, SCage, Ngrouping, Footfalls, $\left.G_{B i}\right)$

In Model 6 and Model 7, more adjustment variables are used to refine the ability to explain the dependent variable Lnrentsqf $_{\boldsymbol{i}}$. These include regional retail rental level $(\boldsymbol{R} \boldsymbol{R} \boldsymbol{R} \boldsymbol{L})$ and other tenant and shopping centre characteristic variables such as the strong tenants, size of tenant, strength of chain, age of the shopping centre and the weekly footfall. The reason for separating these two indices is, once again, to avoid the multicollinearity problem. 


\section{3-3-4 The core/ periphery retail/service categories from factor analysis}

In the original dataset, there are more than 90 retail categories. With so many variables at the same time, we need to use a multivariate statistical technique - factor analysis - to reduce the dimensions of these variables. Factor analysis is an exploratory statistical technique which "addresses the problem of analysing the structure of the interrelationships (correlations) among a large number of variables (e.g., test scores, test items, questionnaire response) by defining a set of common underlying dimensions, known as factors." (Hair et al., 1998, p 90)

This test was designed by using the overall tenant list (around 12,000 records were collected) and the retail categories (around 90 categories) of each tenant in the 148 regional shopping centres. By using factor analysis (specifically, the principal component method), we should be able to extract key factors. These significant factors can be put back into our multi-regression model to reconfirm the significance of the extracted factors. The whole analysis process is described as followed:

1. The model uses the number of tenants in the 28 retail/service categories (see Table 2), generated from our 148 shopping centre database to run the factor analysis process in SAS programme.

\begin{tabular}{|l|l|l|l|}
\hline \multicolumn{4}{|c|}{ Table 2: 28 retail/service categories after re-categorising } \\
\hline 1 & Accessories \& Jewellery & 15 & Leisure \\
\hline 2 & Books, Cards \& Stationery & 16 & Music and Video \\
\hline 3 & Clothing - Childrenswear/babywear & 17 & Non-Supermarket Food Retailer \\
\hline 4 & Clothing - Discount/value retail & 18 & Pets \& Accessories \\
\hline 5 & Clothing - Menswear & 19 & Pharmacy Health \& Beauty \\
\hline 6 & Clothing - Unisex & 20 & Restaurants Bars \& Cafes \\
\hline 7 & Clothing - Womenswear & 21 & Services - General \\
\hline 8 & Crafts Hobbies \& Toys & 22 & Services - Financial \\
\hline 9 & Department , Variety, Value and Catalogue Store & 23 & Services - Retailing \\
\hline 10 & Drink \& CTN & 24 & Sports \\
\hline 11 & Electrical \& Computer Goods & 25 & Supermarket \\
\hline 12 & Footwear & 26 & Telecommunications \\
\hline 13 & Gifts, Antiques \& Art & 27 & Themed Store \\
\hline 14 & Household Goods & 28 & Unknown \\
\hline
\end{tabular}

2. By using the number of unit of each retail/service categories of each shopping centre, we can use the factor analysis based on principal component methods to identify common factors explaining variations. 
3. The factors were selected using Latent Roots Criterion (Hair et al., 1998, p103) which identifies those factors with Eigenvalues equal to or greater than one. The overall communality of these extracted factors should above 60 to 70 percent.

4. After the factors are extracted, we then start to define them based on the content of these factors and retail/tenant mix related theory. The factors are rotated to improve definition.

5. Finally, the scores of these factors are calculated for each centre and then put into a multiple-regression model to see if the regression results confirm hypothesis $\mathrm{H}_{\mathrm{d}}$.

\section{Empirical results}

\section{4-1 Tenant mix variety indices}

Shopping centre characteristics relating to variety, image and overall customer drawing power were examined. We tested the overall size of the shopping centre, the number of units, the average unit size, number of retail/service categories and number of brands. Each of these variables has its own meaning related to the variety of shopping centres. The hypotheses for all these five variables were that they should have a positive relationship with rent/ sq. ft., showing that more variety has a benefit to the shopping centre. Since these five variables are illustrating centre variety, we should expect them to be highly correlated and, hence, it is inappropriate to test them in the same multi-regression model due to multicollinearity. Consequently, for Models 1 to 5 , we use five simplified two-variable regressions to test these five variety variables. The variable tenant size groups (Sgrouping) is added to the model to increase the R-square and specification of each test. Sgrouping was also tested in Model 6 and Model 7 and proved to be highly influential on tenant rent. Tenant size is also a strongly individual tenant characteristic; we thus expect there should be minimum multicollinearity while testing other shopping centre characteristic variables. 


\begin{tabular}{|c|c|c|c|c|c|c|c|c|}
\hline \multicolumn{9}{|c|}{ Dependent variable LnY: Logarithm of adjusted rent per square foot } \\
\hline & \multicolumn{8}{|c|}{ Model 1} \\
\hline Variable & Coef & $\underline{S E}$ & t-Stat & Prob. & R-sq & Ad R-sq & F-stat & Prob \\
\hline Sgrouping & -0.466 & 0.02 & -20.04 & 0.00 & & & & \\
\hline SCsize & 0.00001 & 0.00 & 11.68 & 0.00 & 0.310 & 0.309 & 407.85 & 0.0000 \\
\hline \multirow[t]{2}{*}{$\mathrm{C}$} & 4.109 & 0.05 & 84.07 & 0.00 & & & & \\
\hline & \multicolumn{8}{|c|}{ Model 2} \\
\hline Variable & Coef & $\underline{S E}$ & t-Stat & Prob. & R-sq & Ad R-sq & F-stat & Prob \\
\hline Sgrouping & -0.456 & 0.02 & -19.47 & 0.00 & & & & \\
\hline SCunits & 0.003 & 0.00 & 9.23 & 0.00 & 0.286 & 0.285 & 363.88 & 0.0000 \\
\hline \multirow[t]{2}{*}{ C } & 4.133 & 0.05 & 79.33 & 0.00 & & & & \\
\hline & \multicolumn{8}{|c|}{ Model 3} \\
\hline Variable & Coef & $\underline{S E}$ & $\underline{t-S t a t}$ & $\underline{\text { Prob. }}$. & R-sq & Ad R-sq & F-stat & Prob \\
\hline Sgrouping & -0.471 & 0.02 & -20.26 & 0.00 & & & & \\
\hline Ausize & 0.00005 & 0.00 & 6.91 & 0.00 & 0.265 & 0.265 & 328.48 & 0.0000 \\
\hline \multirow[t]{2}{*}{ C } & 4.157 & 0.06 & 74.11 & 0.00 & & & & \\
\hline & \multicolumn{8}{|c|}{ Model 4} \\
\hline Variable & Coef & $\underline{S E}$ & t-Stat & Prob. & R-sq & Ad R-sq & F-stat & Prob \\
\hline Sgrouping & -0.457 & 0.02 & -19.38 & 0.00 & & & & \\
\hline NOFCATE & 0.007 & 0.00 & 2.84 & 0.00 & 0.253 & 0.252 & 307.52 & 0.0000 \\
\hline \multirow[t]{2}{*}{ C } & 4.200 & 0.09 & 45.91 & 0.00 & & & & \\
\hline & \multicolumn{8}{|c|}{ Model 5} \\
\hline Variable & Coef & $\underline{S E}$ & $\underline{t-S t a t}$ & Prob. & R-sq & Ad R-sq & F-stat & Prob \\
\hline Sgrouping & -0.454 & 0.02 & -19.47 & 0.00 & & & & \\
\hline NOFBRANDS & 0.004 & 0.00 & 11.87 & 0.00 & 0.303 & 0.302 & 395.12 & 0.0000 \\
\hline C & 4.056 & 0.05 & 79.77 & 0.00 & & & & \\
\hline \multicolumn{9}{|c|}{ White Heteroskedasticity-Consistent Standard Errors \& Covariance } \\
\hline \multicolumn{9}{|c|}{ Sample(adjusted): 11924} \\
\hline Included observa & tions: 1821 & Excl & ed observ & ions: 1 & after ad & Isting endp & oints & \\
\hline
\end{tabular}

\section{4-1-1 Shopping centre size}

Table 3, Model 1 shows that the variable SCsize is positively significantly related to tenant rent per square foot (at $\alpha=1 \%$ ). This implies that the larger the shopping centre, the higher the individual tenant rent. Retailers or service providers who take the spaces still have to pack their business area effectively with enough goods and services to make sufficient transactions to generate profits. 
Therefore, in general, the larger the shopping centre the higher the variety and the higher the individual rent level, confirmed in Table 3. Similar results can be found in Benjamin et al. (1992), Sirmans and Guidry (1993), Gatzlaff et al. (1994) and Tay et al. (1999).

\section{4-1-2 Number of units}

The number of units in a shopping centre is another index for shopping centre variety. Generally speaking, the higher the number of units the higher the variety, which means the rent level is higher. In Table 3, Model 2 the coefficient for SCunits is positive significant (at $\alpha=1 \%$ ) to rent/sq $\mathrm{ft}$, which confirms this hypothesis. Unlike shopping centre size, the number of units of a shopping centre indicates the division of the overall space. More units normally means more variety in retail/service tenants, although some of the individual retailers may take two or more units. However, identical retailers increase competition and decrease variety thus reducing monopoly power.

Consequently, we expect the larger the number of units, the higher the tenant mix variety. Table 4 shows that the correlation coefficient between unit number and brands is very high which supports the view that the higher the unit number the more variety of brands in the shopping centre.

\begin{tabular}{|c|c|c|}
\hline \multicolumn{3}{|c|}{$\begin{array}{l}\text { Table 4: Correlation coefficient between unit and brand } \\
\text { number of UK regional shopping centres }\end{array}$} \\
\hline & SC Units & Number of brands \\
\hline SC Units & 1 & \\
\hline Number of brands & 0.92 & 1 \\
\hline
\end{tabular}

\section{4-1-3 Average unit size}

The third index for tenant mix variety is the average unit size in a shopping centre. We can interpret this variable as a characteristic of both the shopping centre and the retailer, since larger average unit size of the retailer means more space for merchandise and services. Table 3, Model 3 confirms that a larger average unit size has a positive effect on individual tenant rent. There is a trade-off between the three factors, namely the shopping centre size, unit number and average unit size. For a given shopping centre size, more units mean a smaller average unit size. Therefore, other things been equal, only the largest shopping centre can both have a high number of unit and a large average unit size. 
Of course, we should also consider that the anchor tenants and major space users may take most of the spaces. Average unit size is positively significantly related (at $\alpha=1 \%$ ) to rent/ sq ft suggesting that size effects dominate mix in this case.

\section{4-1-4 Number of retail/service categories}

The fourth index in this section is the absolute number of retail/service categories. Of course, the demand for variety should mean the more retail/service categories the better. The results shown in Table 3, Model 4 also confirm our hypothesis that the more retail categories in the centre, the higher the individual tenant rent/sq $\mathrm{ft}$. This result does not contradict the results using the Herfindahl index of retail/service categories shown below. In contrast, it gives more information about tenant mix variety; it is better for a shopping centre to have more retail/service categories. At the same time, as we will see, the centre should concentrate on "core" retail/service categories, which leads to certain policy implications.

\section{4-1-5 Number of brands}

The fifth and last index of tenant mix variety in this section is the number of brands in a shopping centre. Certainly, the larger the number of brands the higher the variety and rent/sq $\mathrm{ft}$. Table 3, Model 5 shows that number of brands is positive significant to rent/sq ft at $\alpha=1 \%$.

\section{4-2 Concentration and diversity - Herfindahl index of retail/service categories and brands}

In the discussion on agglomeration, we suggested that there should be rules or principles of compatibility in retail agglomeration: otherwise the cluster could be more chaotic than beneficial. In our database, there are 90 retail/service categories and 3,219 different brands in all 148 UK regional shopping centres. Centre managers/operators thus face a major selection problem: how to achieve the "best" or "ideal" tenant mix? From hypothesis $\mathrm{H}_{\mathrm{b}}$, we suggested that the "core" of the agglomeration should be established through the concentration on certain retail/service categories. Hypothesis $\mathrm{H}_{\mathrm{c}}$ suggested that the diversity of brands also helps to deepen the selection of merchandises and services in these categories. Therefore, to establish its core retail/service categories and also provide a wide selection in brands, a shopping centre should concentrate on dominant retail/service categories. 
The results of Model 6 and Model 7 are shown in Table 5. In Model 6, the Herfindahl index of retail/service categories $\left(G_{C i}\right)$ is positively significantly related to rent per square foot. By contrast, the Herfindahl index of brands $\left(G_{B i}\right)$ is negative significant to tenant rent (both significant at $\alpha=1 \%$ ).

\begin{tabular}{|c|c|c|c|c|c|c|c|c|}
\hline \multirow{3}{*}{\multicolumn{5}{|c|}{\begin{tabular}{|l|}
\multicolumn{2}{|c}{ Table 5: The multi-regression results of Herfindahl indice } \\
Dependent variable LnY: Logarithm of adjusted rent per square foot \\
\end{tabular}}} & \multicolumn{4}{|c|}{$s$ of categories and brands } \\
\hline & & & & & & & & \\
\hline & & & & & \multicolumn{4}{|c|}{ Model 7} \\
\hline Variable & $\underline{\text { Coeffi }}$ & $\underline{S E}$ & $\underline{t-S t a t}$ & $\underline{\text { Prob. }}$ & $\underline{\text { Coeffi }}$ & $\underline{S E}$ & $\underline{t \text {-Stat }}$ & $\underline{\text { Prob. }}$. \\
\hline RRRL & 0.001 & 0.00 & 3.36 & 0.00 & 0.001 & 0.00 & 3.33 & 0.00 \\
\hline STenant & -0.088 & 0.04 & -2.32 & 0.02 & -0.093 & 0.04 & -2.44 & 0.01 \\
\hline SCage & -0.009 & 0.00 & -5.87 & 0.00 & -0.012 & 0.00 & -7.93 & 0.00 \\
\hline Sgrouping & -0.486 & 0.02 & -20.33 & 0.00 & -0.475 & 0.02 & -19.54 & 0.00 \\
\hline Ngrouping & 0.151 & 0.02 & 8.19 & 0.00 & 0.156 & 0.02 & 8.50 & 0.00 \\
\hline Footfalls & 0.000 & 0.00 & 9.12 & 0.00 & 0.000 & 0.00 & 8.25 & 0.00 \\
\hline$G_{C i}$ & 5.983 & 1.23 & 4.87 & 0.00 & & & & \\
\hline$G_{B i}$ & & & & & -9.390 & 3.19 & -2.94 & 0.00 \\
\hline $\mathrm{C}$ & 3.497 & 0.12 & 30.38 & 0.00 & 4.120 & 0.10 & 41.85 & 0.00 \\
\hline R-squared & & & 41 & & & & & \\
\hline Adj R-squared & & & 41 & & & & 40 & \\
\hline F-statistic & & & .06 & & & & .31 & \\
\hline Prob (F-statistic) & & & 00 & & & & 00 & \\
\hline \multicolumn{9}{|c|}{ White Heteroskedasticity-Consistent Standard Errors \& Covariance } \\
\hline \multicolumn{9}{|c|}{ Sample(adjusted): 11920} \\
\hline \multicolumn{9}{|l|}{ Included observations: 1615} \\
\hline Excluded observations: 30 & adil & & & & & & & \\
\hline
\end{tabular}

The result from Model 6 (Table 5) means the higher the Herfindahl index of retail/service categories, the higher the rent, which implies that more concentration within retail/service categories can improve the rent level. The result from Model 7 (Table 5) tells us that the lower the Herfindahl index of brands the higher the rent; our interpretation of this is the more evenly spread (diverse) are the brands, the higher the rents. Both results confirmed our hypotheses $\mathrm{H}_{b}$ and $\mathrm{H}_{c}$. Nevertheless, we have no information on which are the key retail/service categories from these regression models. Therefore, we will use factor analysis of retail/service categories to shed light on the "core" retail categories. Only by concentrating on the core retail/service categories is it possible to acquire the greatest agglomeration economies. 


\section{4-3 Factor analysis of retail/service categories}

\section{4-3-1 Extraction of representative factors}

In the previous section, several effective indices for tenant mix variety were tested. However, from these variety indices, we are still unable which categories should form the core of a tenant mix strategy We need further analysis to acquire this specific information. In this section, we use tenant mix data from the 148 UK regional shopping centres and factor analysis to extract the representative dimensions of the retail/service categories.

Table 6: Factor analysis (1)-Eigenvalues of the top 10 factors

SAS Procedure: The FACTOR Procedure

Initial Factor Method: Principal Components

Prior Communality Estimates: ONE

Eigenvalues of the Correlation Matrix: Total $=28 \quad$ Average $=1$

\begin{tabular}{|c|c|c|c|c|}
\hline & Eigenvalue & Difference & Proportion & Cumulative \\
\hline 1 & 10.9549 & 7.2659 & 0.3912 & 0.3912 \\
\hline 2 & 3.6890 & 1.7292 & 0.1318 & 0.5230 \\
\hline 3 & 1.9598 & 0.7082 & 0.0700 & 0.5930 \\
\hline 4 & 1.2517 & 0.1564 & 0.0447 & 0.6377 \\
\hline 5 & 1.0953 & 0.0953 & 0.0391 & 0.6768 \\
\hline 6 & 1.0000 & 0.0283 & 0.0357 & 0.7125 \\
\hline 7 & 0.9717 & 0.2486 & 0.0347 & 0.7472 \\
\hline 8 & 0.7230 & 0.0756 & 0.0258 & 0.7731 \\
\hline 9 & 0.6474 & 0.0873 & 0.0231 & 0.7962 \\
\hline 10 & 0.5602 & 0.0194 & 0.0200 & 0.8162 \\
\hline
\end{tabular}

\begin{tabular}{|c|c|c|c|c|c|}
\hline \multicolumn{7}{|c|}{ Table 7: Factor analysis (2)-variance explained by each factor } \\
\hline Factor1 & Factor2 & Factor3 & Factor4 & Factor5 & Factor6 \\
\hline $39.1 \%$ & $13.2 \%$ & $7.0 \%$ & $4.5 \%$ & $3.9 \%$ & $3.6 \%$ \\
\hline
\end{tabular}

From Table 6, we can see that by using the latent roots criterion (Hair et al., 1998, p103), the first six factors have Eigenvalues equal to or greater than one, that is, more significant than a single variable. These six factors explain $71.25 \%$ of the variation in tenant mix though only Factor 1 and Factor 2 have Eigenvalues greater than 2. Table 6 and Table 7 show Factor 1 with eigenvalue 10.95 and about $40 \%$ contribution to total variance and Factor 2 with eigenvalue 3.69 and a 13.2\% contribution to total variance. From these results, the first 6 factors were extracted for further analysis. However, we expect Factor 1 and 2 to be more highly representative and related to rents than other factors. 


\section{4-3-2 Extracted factor analysis and factor rotations}

It is difficult for us to generate definitions and meanings of factors from the unrotated pattern. Therefore, we apply the most commonly used orthogonal rotation method, the Varimax, and another oblique method (Promax) ${ }^{5}$ provided by SAS software to generate rotated factor patterns and loading matrixes for further interpretation of the factors. The criteria for the significance of factor loadings can be seen in Hair et al. (1998, p111). They suggested that when the sample size is 100 or larger (in our database, the sample size is 148), factor loadings greater than \pm .30 are considered to meet the minimal level; loadings of \pm .40 are considered more important; and if the loadings are \pm .50 or greater, they are considered of practical significance. Thus the larger the absolute size of the factor loading, the more important the loading is in interpreting the factor matrix.

\begin{tabular}{|c|c|c|c|c|c|c|}
\hline & Factor1 & Factor2 & Factor3 & Factor4 & Factor5 & Factor6 \\
\hline Clothing - Womenswear & 0.8991 & 0.2130 & 0.0950 & -0.0679 & 0.0349 & 0.0412 \\
\hline Restaurants Bars \& Cafes & 0.8666 & -0.0195 & 0.1961 & 0.0693 & 0.0334 & 0.1191 \\
\hline Clothing - Menswear & 0.8521 & 0.1305 & 0.0226 & -0.0560 & 0.2152 & 0.0893 \\
\hline Accessories \& Jewellery & 0.8352 & 0.3736 & 0.1485 & -0.0351 & -0.0152 & 0.0332 \\
\hline Gifts, Antiques \& Art & 0.8161 & 0.1580 & 0.1064 & 0.0990 & -0.1005 & 0.1210 \\
\hline Clothing - Unisex & 0.7882 & 0.0136 & -0.0087 & -0.0843 & 0.3536 & -0.0392 \\
\hline Crafts Hobbies \& Toys & 0.7808 & 0.1878 & 0.3080 & 0.0451 & -0.0369 & -0.0828 \\
\hline Themed Store & 0.6922 & 0.1460 & -0.0700 & 0.2061 & -0.1589 & 0.0897 \\
\hline Footwear & 0.6873 & 0.3092 & 0.2727 & -0.0208 & 0.2549 & 0.0414 \\
\hline Childrenswear/Babywear & 0.6677 & 0.1265 & 0.2485 & 0.0176 & 0.3389 & -0.0601 \\
\hline Sports Stores & 0.6484 & 0.5202 & 0.1310 & -0.0091 & 0.1486 & 0.1174 \\
\hline Department, Variety, Value and Catalogue & -0.0433 & 0.7809 & 0.2044 & 0.1006 & 0.1622 & -0.0198 \\
\hline Telecommunications & 0.4117 & 0.7470 & 0.1403 & -0.1984 & -0.0574 & 0.0256 \\
\hline Electrical \& Computer Goods & 0.3130 & 0.7214 & -0.0475 & 0.2417 & 0.1422 & 0.1648 \\
\hline Books, Cards \& Stationery & 0.3613 & 0.6977 & 0.2080 & 0.1105 & 0.0621 & 0.0418 \\
\hline Pharmacy Health \& Beauty & 0.4642 & 0.5901 & 0.3866 & 0.2247 & -0.0356 & 0.2095 \\
\hline Drink \& CTN & 0.0956 & 0.1059 & 0.7536 & 0.2815 & 0.0855 & -0.0629 \\
\hline Non-Supermarket Food Retailer & 0.4271 & 0.1646 & 0.6345 & 0.0751 & 0.1930 & 0.0734 \\
\hline Music and Video & 0.3623 & 0.2737 & 0.6114 & 0.0020 & 0.0695 & 0.1856 \\
\hline Services - Retailing & 0.0594 & 0.4066 & 0.5013 & 0.4700 & 0.1664 & 0.3582 \\
\hline Services - General & 0.1238 & 0.3015 & -0.0141 & 0.7533 & 0.0811 & -0.1737 \\
\hline Leisure & 0.1046 & -0.1886 & 0.1988 & 0.7209 & 0.0837 & 0.3387 \\
\hline Supermarket & -0.2434 & 0.0614 & 0.2698 & 0.6926 & 0.1655 & 0.1501 \\
\hline Services - Financial & 0.0645 & 0.2853 & 0.4288 & 0.4149 & 0.1884 & 0.4299 \\
\hline Household Goods & 0.3977 & 0.0490 & 0.0749 & 0.3351 & 0.6860 & -0.1015 \\
\hline Clothing - Discount/value retail & -0.0612 & -0.0020 & 0.0812 & 0.2139 & 0.7290 & 0.1771 \\
\hline Pets \& Accessories & 0.1395 & 0.1165 & 0.0591 & 0.1221 & 0.1645 & 0.8477 \\
\hline Unknown & 0.0937 & 0.2235 & 0.1237 & -0.0530 & 0.4549 & 0.1199 \\
\hline
\end{tabular}

\footnotetext{
${ }^{5}$ See the SAS software online help for "Proc Factor".
} 
Using these criteria, we can select representative variables with high loadings of each factor. Table 8 shows that by using the Varimax rotation method, the coloured (shaded) loadings of each factor are the representative variables. The factor loadings in Table 9 provide the same information for the Promax rotation. Later, we calculate the scores of Factor 1 and Factor 2 for further tests.

\begin{tabular}{|c|c|c|c|c|c|c|}
\hline \multicolumn{7}{|c|}{$\begin{array}{l}\text { Table 9: Factor analysis (4)- factor structure matrix (correlations) } \\
\text { Promax rotation method }\end{array}$} \\
\hline & Factor1 & Factor2 & Factor3 & Factor4 & Factor5 & Factor6 \\
\hline Clothing - Womenswear & 0.9279 & 0.4442 & 0.2937 & -0.0510 & 0.1226 & 0.1392 \\
\hline Accessories \& Jewellery & 0.8949 & 0.5877 & 0.3629 & -0.0062 & 0.0753 & 0.1595 \\
\hline Clothing - Menswear & 0.8747 & 0.3570 & 0.2338 & -0.0304 & 0.2907 & 0.1724 \\
\hline Restaurants Bars \& Cafes & 0.8705 & 0.2475 & 0.3662 & 0.0891 & 0.1388 & 0.2249 \\
\hline Gifts, Antiques \& Art & 0.8326 & 0.3825 & 0.2983 & 0.1082 & -0.0014 & 0.2252 \\
\hline Crafts Hobbies \& Toys & 0.8219 & 0.4205 & 0.4556 & 0.0652 & 0.0700 & 0.0638 \\
\hline Clothing - Unisex & 0.7944 & 0.2222 & 0.1644 & -0.0696 & 0.4166 & 0.0293 \\
\hline Footwear & 0.7722 & 0.5271 & 0.4776 & 0.0469 & 0.3381 & 0.1923 \\
\hline Sports Stores & 0.7502 & 0.6937 & 0.3820 & 0.0550 & 0.2196 & 0.2574 \\
\hline Childrenswear/babywear & 0.7221 & 0.3457 & 0.4163 & 0.0666 & 0.4217 & 0.0793 \\
\hline Themed Store & 0.6861 & 0.3129 & 0.1151 & 0.1853 & -0.0729 & 0.1679 \\
\hline Telecommunications & 0.5402 & 0.8187 & 0.3241 & -0.1390 & -0.0244 & 0.1347 \\
\hline Books, Cards \& Stationery & 0.5001 & 0.8000 & 0.4360 & 0.1823 & 0.1264 & 0.2166 \\
\hline Electrical \& Computer Goods & 0.4404 & 0.7909 & 0.2451 & 0.3043 & 0.1937 & 0.3157 \\
\hline Department, Variety, Value and Catalogue & 0.1238 & 0.7770 & 0.3803 & 0.1880 & 0.1853 & 0.1434 \\
\hline Pharmacy Health \& Beauty & 0.6006 & 0.7674 & 0.6270 & 0.3154 & 0.0638 & 0.4169 \\
\hline Drink \& CTN & 0.1967 & 0.2681 & 0.7861 & 0.3707 & 0.1830 & 0.1552 \\
\hline Non-Supermarket Food Retailer & 0.5291 & 0.3892 & 0.7479 & 0.1767 & 0.2889 & 0.2650 \\
\hline Music and Video & 0.4767 & 0.4679 & 0.7252 & 0.1117 & 0.1502 & 0.3550 \\
\hline Services - Retailing & 0.2069 & 0.5497 & 0.7103 & 0.6001 & 0.2563 & 0.5851 \\
\hline Services - Financial & 0.1873 & 0.4268 & 0.6228 & 0.5393 & 0.2658 & 0.6169 \\
\hline Leisure & 0.1120 & -0.0406 & 0.3403 & 0.7603 & 0.1807 & 0.4789 \\
\hline Supermarket & -0.1785 & 0.1095 & 0.3753 & 0.7511 & 0.2328 & 0.3189 \\
\hline Services - General & 0.1740 & 0.3596 & 0.1808 & 0.7427 & 0.1745 & 0.0207 \\
\hline Household Goods & 0.4514 & 0.2152 & 0.2828 & 0.3850 & 0.7584 & 0.0599 \\
\hline Clothing - Discount/value retail & 0.0074 & 0.0657 & 0.2213 & 0.3070 & 0.7402 & 0.2677 \\
\hline Pets \& Accessories & 0.2037 & 0.2327 & 0.2672 & 0.2397 & 0.1844 & 0.8768 \\
\hline Unknown & 0.1789 & 0.2866 & 0.2475 & 0.0307 & 0.4612 & 0.1936 \\
\hline
\end{tabular}

\section{4-3-3 Definitions of the factors}

The next step in factor analysis is to define and name the extracted factors based on the factor loadings. This procedure relies on the researchers' own interpretation. Both Varimax and Promax methods gave consistent results. Variables with higher loadings are most important in labelling a factor - they lie closest to the rotated factor in multidimensional variance space. Table 10 provides labels and interpretations for the six factors rotated. 


\begin{tabular}{|c|c|c|}
\hline \multicolumn{3}{|c|}{ Table 10: Factor analysis (5)- the labelling process of the factors } \\
\hline Factor 1: Fashion and Comparison Variety & & \\
\hline \multirow{2}{*}{ Representative retail/service categories } & \multicolumn{2}{|c|}{ Loadings } \\
\hline & Varimax & Promax \\
\hline Clothing - Womenswear & 0.90 & 0.93 \\
\hline Restaurants Bars \& Cafes & 0.87 & 0.87 \\
\hline Clothing - Menswear & 0.85 & 0.87 \\
\hline Accessories \& Jewellery & 0.84 & 0.89 \\
\hline Gifts, Antiques \& Art & 0.82 & 0.83 \\
\hline Clothing - Unisex & 0.79 & 0.79 \\
\hline Crafts Hobbies \& Toys & 0.78 & 0.82 \\
\hline Themed Store & 0.69 & 0.69 \\
\hline Footwear & 0.69 & 0.77 \\
\hline Clothing - Childrenswear/babywear & 0.67 & 0.72 \\
\hline Sports & 0.65 & 0.75 \\
\hline \multicolumn{3}{|c|}{ Factor 2: Selective Goods, Information and Health } \\
\hline $\begin{array}{l}\text { Representative retail/service categories } \\
\end{array}$ & Varimax & Promax \\
\hline Department, Variety, Value and Catalogue Store & 0.78 & 0.78 \\
\hline Telecommunications & 0.75 & 0.82 \\
\hline Electrical \& Computer Goods & 0.72 & 0.79 \\
\hline Books, Cards \& Stationery & 0.70 & 0.80 \\
\hline Pharmacy Health \& Beauty & 0.59 & 0.77 \\
\hline \multicolumn{3}{|l|}{ Factor 3: Supportive and Fun } \\
\hline Representative retail/service categories & Varimax & Promax \\
\hline Drink \& CTN & 0.75 & 0.79 \\
\hline Non-Supermarket Food Retailer & 0.63 & 0.75 \\
\hline Music and Video & 0.61 & 0.73 \\
\hline Services - Retailing & 0.50 & 0.71 \\
\hline Services - Financial & & 0.62 \\
\hline \multicolumn{3}{|l|}{ Factor 4: Leisure, Services and Daily Needs } \\
\hline Representative retail/service categories & Varimax & Promax \\
\hline Services - General & 0.75 & 0.74 \\
\hline Leisure & 0.72 & 0.76 \\
\hline Supermarket & 0.69 & 0.75 \\
\hline Services - Financial & 0.41 & \\
\hline \multicolumn{3}{|l|}{ Factor 5: Value and Household } \\
\hline Representative retail/service categories & Varimax & Promax \\
\hline Household Goods & 0.69 & 0.76 \\
\hline Clothing - Discount/value retail & 0.73 & 0.74 \\
\hline \multicolumn{3}{|l|}{ Factor 6: Others (Pets) } \\
\hline Representative retail/service categories & Varimax & Promax \\
\hline Pets \& Accessories & 0.85 & 0.88 \\
\hline
\end{tabular}

The result of the representative variables for Factor 1 is consistent with both Varimax and Promax procedures, although the ranking of some of the loadings is slightly different. These factor patterns show that the "core" retail/service categories of the tenant mix in UK regional centres are mainly fashion (clothing for women, menswear and childrenswear, accessories and jewellery, and themed stores), and other comparative goods (gifts, antiques, arts, toys, footwear and sports goods). This factor 
contributes $40 \%$ of the total variance, the highest of all factors. Therefore, we labelled Factor 1 as "Fashion, and Comparison Variety". There are also high factor loadings for dining/refreshments (restaurants, bars and cafés) which may be linked to the size of outlet. These retail/service categories fulfil the main purpose for the shoppers in regional shopping centres. To some extent, the first factor in a rotation tends to pick up "greatest" source of variation in the dataset. Thus this factor represents the core elements of the representative shopping centre.

Factor 2 is the factor with the second highest eigenvalue (3.69) and contributes 13.1\% of the total variance. Although these two values are both far lower than Factor 1, Factor 2 is more significant in terms of variance than the later factors (Factor 3 contributes only $7 \%$ of the variance and other later Factors less than 5\%). The representative variables in Factor 2 are selective goods (large stores: department stores, variety, value and catalogue stores), information goods (telecommunication, electrical and computer goods, books, cards and stationary), and health (pharmacy health and beauty). Here, we name this factor as "Selective Goods, Information and Health”

The representative variables of Factor 3 are supportive goods (drink \& CTN, non-supermarket food, services - retailing, service-financial ${ }^{6}$ ) and fun (music and video). We labelled Factor 3 "Supportive and Fun". However, we note that the eigenvalue of Factor 3 is only 1.96 and contributes only $7 \%$ of the total variance. Although still above the criterion of factor selection (eigenvalue above 1), it is far lower than the contribution made by Factor 1 and Factor 2. Thus we decided that the factors after Factor 3 are not “core” factors for analysis of tenant mix variety.

Factor 4 is related to the retail/service categories of leisure (leisure), services (services - general, services - finance) and daily needs (supermarket) - "Leisure, Services and Daily Needs" The eigenvalue of this factor is only 1.25 and makes less than $5 \%(4.47 \%)$ contribution to explaining overall variance.

Factor 3 and Factor 4 are opposite retail/service categories to Factor 1 and Factor 2. The categories in Factor 1 and Factor 2 are the "core" of the shopping centre retail agglomeration and focus on "comparative goods", Factor 3 and Factor 4 are more "peripheral” to the centre (although weaker centres might be dominated by such

\footnotetext{
${ }^{6}$ Service financial is the only variable for which we can not decide the exact location, for the loadings are close in Varimax method, it could be placed in either Factor 3, 4 or 6. But it is clear that in Promax method, it is in Factor 4, though the loading is very weak (around 0.15-0.2 in Promax) so it is clearly not a major explanatory category.
} 
outlets) and are dominated by “convenience goods” and lower order functions.

Factor 5 and Factor 6 both contribute only around 4\% (3.9\% for Factor 5 and 3.5\% for Factor 6) of the total variance. The representative variables of Factor 5 are value (clothing - discount/value retail) and household (household goods). We labelled this factor "Value and Household". Factor 6 has only one representative category, which is the pets and accessories. This is a rather weak factor and so we simply named it as “Others (Pets)". The last factor in a rotation tends to clean up the remaining variation, with many low loadings so it would be misleading to over-interpret such a factor.

\section{4-3-4 Multi-regression results with the factor scores}

Factors 1 and 2 are the "core” factors from the above factor analysis. We calculate the factor scores of Factor 1 and Factor 2 from all three methods and test their relationship with rent/sq ft. The prior hypothesis is these two core factors with higher loadings at their representative variables should show a positive relationship with the performance index, i.e. the rent. A shopping centre with greater weight on these two factors can have better performance - which should be reflected in individual tenancy rents. In other words, if the tenant mix strategies of a shopping centre concentrate on these "core" retail/service categories, such centres can have a higher performance than the others.

The results from Table 11 show that the factor score of Factor 1 from all three methods (even the original unrotated factor patterns from the principal component method) gives us a positive significant relationship (at $\alpha=1 \%$ ) with rent/sq $\mathrm{ft}$. This means that the higher the score of Factor 1, the higher the rents, consistent with our prior hypothesis.

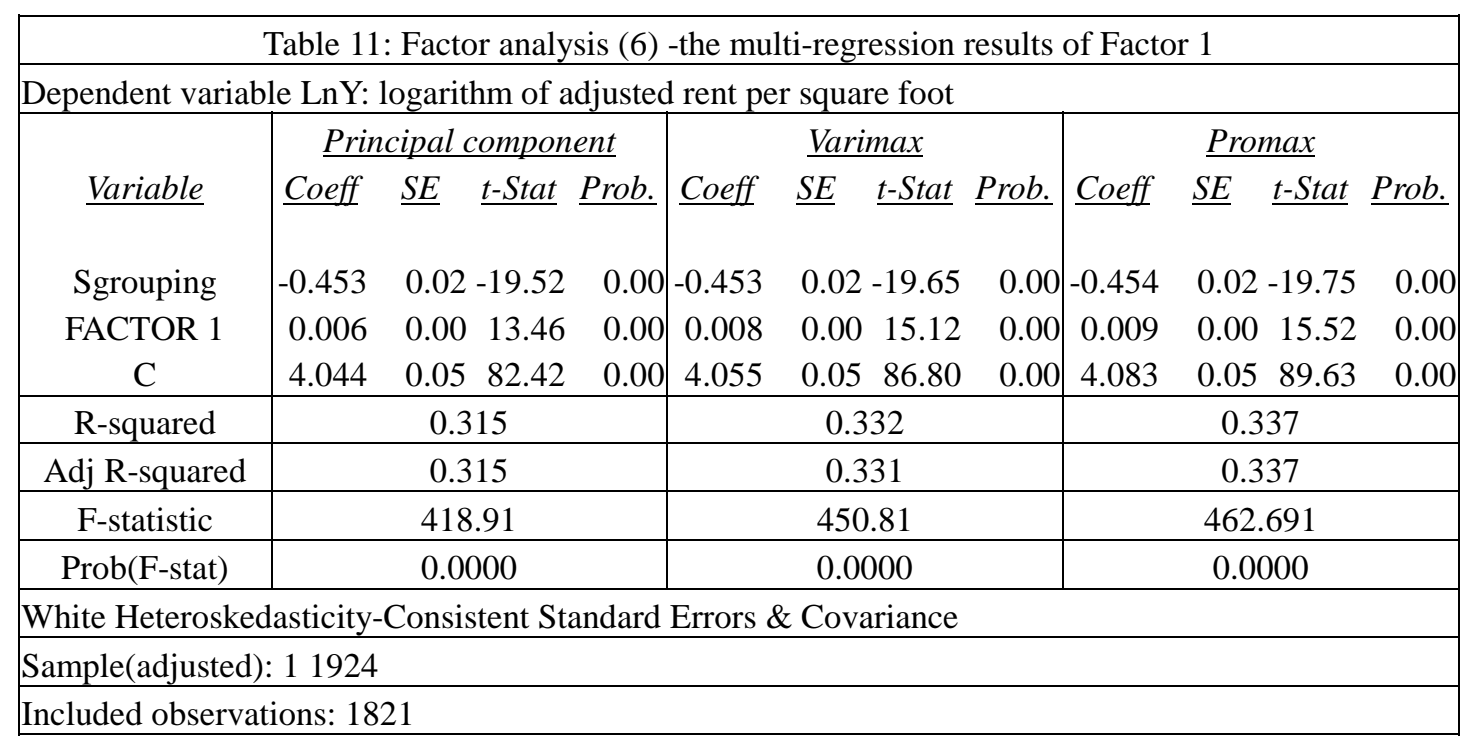


Excluded observations: 103

The variable Factor 2 also gives a positive significant result (Table 12) using the Varimax and Promax method although the result from the unrotated principal component solution is not significant.

\begin{tabular}{|c|c|c|c|c|c|c|c|c|c|}
\hline \multicolumn{10}{|c|}{ Table 12: Factor analysis (7)-the multi-regression results of Factor2 } \\
\hline \multicolumn{10}{|c|}{ Dependent variable LnY: logarithm of adjusted rent per square foot } \\
\hline & \multicolumn{3}{|c|}{ Principal component } & \multicolumn{3}{|c|}{ Varimax } & \multicolumn{3}{|c|}{ Promax } \\
\hline Variable & Coeff & SE t-Stat & Prob. & Coeff & SE t-Stat & Prob. & Coeff & SE t-Stat & Prob. \\
\hline Sgrouping & -0.455 & $0.02-20.09$ & 0.00 & -0.453 & $0.02-19.34$ & 0.00 & -0.454 & $0.02-19.35$ & 0.00 \\
\hline FACTOR 2 & -0.029 & $0.00-18.58$ & 0.00 & 0.013 & 0.0010 .06 & 0.00 & 0.014 & $0.00 \quad 7.21$ & 0.00 \\
\hline $\mathrm{C}$ & 4.399 & $0.04 \quad 110.8$ & 0.00 & 4.038 & $0.05 \quad 73.54$ & 0.00 & 4.124 & 0.0671 .76 & 0.00 \\
\hline R-squared & \multicolumn{3}{|c|}{0.315} & \multicolumn{3}{|c|}{0.294} & \multicolumn{3}{|c|}{0.275} \\
\hline Adj R-squared & \multicolumn{3}{|c|}{0.315} & \multicolumn{3}{|c|}{0.293} & \multicolumn{3}{|c|}{0.274} \\
\hline F-statistic & \multicolumn{3}{|c|}{418.91} & \multicolumn{3}{|c|}{378.25} & \multicolumn{3}{|c|}{344.362} \\
\hline Prob(F-stat) & \multicolumn{3}{|c|}{0.0000} & \multicolumn{3}{|c|}{0.0000} & \multicolumn{3}{|c|}{0.0000} \\
\hline \multicolumn{10}{|c|}{ White Heteroskedasticity-Consistent Standard Errors \& Covariance } \\
\hline \multicolumn{10}{|c|}{ Sample(adjusted): 11924} \\
\hline \multicolumn{10}{|c|}{ Included observations: 1821} \\
\hline \multicolumn{10}{|c|}{ Excluded observations: 103} \\
\hline
\end{tabular}

Collinearity problem is the major reason for reducing the variables in Table 11 and Table 12 when testing Factor 1 and Factor 2. Since the purpose here is to show that Factor 1 and Factor 2 are positive significant to rent, improving the r-square of the models are not our major concern. We should note that including a fuller specification of rental determinants weakens the significance of Factor 2. However, Factor 1 is consistently positive and significant in a wide range of model specifications, confirming its significance in explaining tenant rent.

\section{Implications}

From our empirical results of tenant mix variety and factor analysis of retail categories we can extract some general principles for tenant mix strategies to distinguish the better tenant mix strategy for shopping centres. We confirmed the following results:
A. The larger the shopping centre, the higher the rent (Model 1).
B. The more units the shopping centre has, the higher the rent (Model 2).
C. The larger the average unit size, the higher the rent (Model 3).
D. The more retail categories, the higher the rent (Model 4).
E. The more brands, the higher the rent (Model 5). 
F. The more concentration in retail/service categories, the higher the rent (Model 6).

G. The more diversity (evenly spread) the brands, the higher the rent (Model 7).

$\mathrm{H}$. The higher the scores on core factors with high loadings in the core categories, here Factor 1 (Fashion and Comparison Variety) and Factor 2 (Selective, Information and Health), the higher the rent.

The beneficial impact of tenant mix variety is the major concern of this paper. Three major aspects can be identified from the above empirical results:

\section{Confirmation of increasing returns from higher variety}

The above results A, B, C, D and E suggest that: the larger shopping centres with the greater number of units, larger average unit size and greater number of retail/service categories and brands are able to achieve higher rents.

\section{Concentration but diversity}

For the product variety, two sub-principles are suggested based on results D, E, F and G:

I Concentrate on the core retail/service categories but including as many categories (peripheral) as possible

II Emphasise diversity in brands

Rule I is the general principle of agglomeration for retail/service categories to generate higher agglomeration economies. It is derived from both the empirical results that the higher the Herfindahl index of retail categories, the higher the rent and also that the more retail/service categories in a shopping centre, the higher the rent. It tells us that a shopping centre should have as many retail/service categories as possible; nevertheless, the agglomeration of these retail categories should be as concentrated as possible.

Rule B, on the other hand, tells us the more diversity in brands the better. In this way, a shopping centre increases its depth of merchandise and services to the customers, i.e. for a certain retail/service category the customers have more comparative variety and 
selection from different retailers and service providers.

\section{The core and periphery retail/service categories}

Although the results point to the existence of a core-peripheral relationship in the retail agglomeration, operationally centre managers/operators of regional shopping centres need to know exactly which retail/service categories should be included in the "core". This is shown in the results from factor analysis.

The representative retail/service categories in Factor 1 (the Fashion and Comparison Variety factor) and Factor 2 (the Selective, Information and Health factor) are identified as "core" categories; other retail/service uses could be seen as "peripheral" categories. Factor 1, in particular, is significantly positively related to rent.

Nevertheless, the tenant mix strategy remains an "art of marketing”. The foregoing dies not suggest that tenant mix strategy of a regional shopping centre should be to solely concentrate on the categories in Factor 1. The empirical results showed that, with higher concentration in Factor 1 and 2 shopping centres can generate higher rents. However, while including other decision-making elements, a centre manager/operator can always have his/her reasons to alter the mix to target a particular niche market. A shopping centre can be successful if it correctly designed and implemented with concentration on other non-Factor 1 categories, including an element of leisure and entertainment. This last has been increasing in importance, though reported profit margins are not as high as the other core categories in Factor 1.

Further, the individual categories found in Factor 1 (the Fashion and Comparison Variety) and Factor 2 (the Selective, Information and Health) are UK based and may be unstable and evolve over time. The rank of the detailed categories might alter slightly in different parts of the world like the US or the Far East area, requiring further, local, research. Nonetheless, these two factors are the essentials of a "regional" shopping centre. This is exactly the notion of Central Place theory, that for the centre of a region (the highest hierarchy), it should contain the highest rank of goods and services (the fashion and comparative variety). 


\section{Conclusion}

A regional shopping centre is meant to fulfil consumers' needs in a region. Consequently it should contain the highest product variety demanded from convenience goods to comparative goods. This variety of the retail agglomeration plays a crucial part in increasing productivity. However, variety is not merely the diversity of product combinations but should include certain principles to maximize the favourable effects that generate increasing returns. In a shopping centre, product variety comes from the combination of retail/service tenants - the tenant mix strategies that are adopted by the manager/operator. Without operational rules, tenant mix decision-making of normally follows a "rule of thumb" or experienced common sense. Therefore, the major aim of this research is to search for beneficial patterns of tenant mix .

The empirical results reveal some of the beneficial patterns of tenant mix. First, the relationship between variety and productivity is confirmed. The five variety-related indices (size of shopping centre, number of units, average unit size, the number of retail/service categories and the number of brands) are all positively related to individual tenant rent. Secondly, the distribution of the retail/service categories should be concentrated on the core categories but with as much variety in categories as possible. At the same time, the higher the diversity of brand names, the greater the contribution to rental level . Third, the core retail/service categories in a regional shopping centre: are Fashion and Comparison Goods and Selective, Information and Health outlets. Regional shopping centres that have a strong concentration in these areas - in particular on the former - generate relatively higher rents. 


\section{References}

Abratt, R., Fourie, J. L., and Pitt, L. F., 1985, Tenant Mix : The Key to a Successful

Shopping Centre: Quarterly Review of Marketing., v. 15, p. 19-27.

AmosWeb, 2003, Herfindahl Index, http://www.amosweb.com/.

Anikeeff, M., 1996, Shopping Centre Tenant Selection and Mix: A Review, in

Benjamin, J. D., ed., Research Issues in Real Estate: Megatrends in Retail Real

Estate, 3, International Council of Shopping Centers and American Real Estate Society, p. 215-238.

Benjamin, J. D., Boyle, G. W., and Sirmans, C. F., 1992, Price discrimination in shopping centre leases: Journal of Urban Economics, v. 32, p. 299-317.

Brown, S., 1991, Tenant Placement in planned shopping centers: implications of an observation survey: Journal of Property Research, v. 8, p. 179-187.

Brown, S., 1992, Tenant Mix, Tenant Placement and Shopper Behavior in a Plan: The Service Industries Journal, v. 12, p. 17-29.

Bruwer, J., 1997, Solving the ideal tenant mix puzzle for a proposed shopping centre: a practical research methodology: Property Management, v. 15, p. 160-172.

Downie, M. L., Fisher, P., and Cheryl, W., 2002, Managing Tenant Mix in Shopping Centres in the United Kingdom: RICS Research Papers, v. 4.

Fischer, J. H., and Harrington Jr., J. E., 1996, Product Variety and Firm Agglomeration: Rand Journal of Economics, v. 27, p. 281-309.

Fujita, M., 1989, Urban Economic Theory: Land Use and City Size, Cambridge Univeristy Press.

Fujita, M., and Thisse, J.-F., 2002, Economics of Agglomeration- Cities, Industrial Location, and Regional Growth, Cambridge University Press.

Gatzlaff, D. H., Sirmans, G. S., and Diskin, B. A., 1994, The Effect of Anchor Tenant Loss on Shopping Center Rents: Journal of Real Estate Research, v. 9, p. 99-110.

Gerbich, M., 1998, Shopping center rentals : An empirical analysis of the retail tenant mix: The Journal of Real Estate Research, p. 283-296.

Getis, A., and Getis, J. M., 1976, Retail store Spatial Affinities, in Rams, E., ed., Analysis and Valuation of Retail Location, Reston Publishing Company, Inc.

Goldstein, G. S., and Gronberg, T. J., 1984, Economies of Scope and Economies of Agglomeration: Journal of Urban Economics, v. 16, p. 91-104.

Greenspan, J., 1987, Solving the tenant mix puzzle in your shopping center: Journal of Property Management, p. 27-31.

Hair, J. F. J., Anderson, R. E., Tatham, R. L., and Black, W. C., 1998, Multivariate Data Analysis, Prentice Hall, Inc.

ICSC, International Council of Shopping Centres., 2002, Official website (US), 
Www.icsc.org.

Kirkup, M. H., and Rafiq, M., 1994, Managing Tenant Mix in New Shopping Centres: International Journal of Retail \& Distribution Management, v. 22, p. 29-37.

Krugman, P., 1991, Increasing Returns and Economic Geography: The Journal of Political Economy, v. 99, p. 483-499.

McCann, P., 2001, Urban and Regional Economics: New York, Oxford University Press.

Nelson, R. L., 1958, The selection of retail location: New York., FW Dodge.

Panzar, J. C., and Willig, R. D., 1981, Economies of Scope: The American Economic Review, v. 71, p. 268-272.

Sirmans, C. F., and Guidry, K. A., 1993, The Determinants of Shopping Center Rents: Journal of Real Estate Research, v. 8, p. 107-115.

Tay, R. S., Lau, C. K., and Leung, M. S., 1999, The determination of rent in shopping centers: some evidence from Hong Kong: Journal of Real Estate Literature, v. 7, p. 183-196.

Urban Land Institute, 1999, Shopping Center Development Handbook, in Spink, F. H., ed., Urban Land Institution.

Wikipedia, 2003, Herfindahl index, From Wikipedia, the free encyclopedia., http://www.wikipedia.org/wiki/Herfindahl_index.

Yuo, T. S.-T., Crosby, N., Lizieri, C., and McCann, P., 2003, The Management of Positive Inter-store Externalities in Shopping Centres-some empirical evidence: Conference paper for European Real Estate Society 2003, Helsinki, 2003. 